\title{
Validity of Endogenous Creatinine Clearance in Low Birthweight Infants
}

\author{
BARBARA S. STONESTREET, EDWARD F. BELL, AND WILLIAM OH
}

Department of Pediatrics, Brown University Program in Medicine, Section of Reproductive and Developmental Medicine, Women and Infants Hospital of Rhode Island, Providence, Rhode Island, USA

\section{Summary}

Despite methodologic problems, endogenous creatinine clearance is commonly used as an estimation of glomerular filtration rate (GFR). Inulin clearance was compared to endogenous creatinine clearance in a group of low birthweight infants to establish the validity of the latter. Thirty-three low birthweight infants (birthweight mean $=1600$ g, gestational age mean $=33$ wk) were studied between $10 \mathrm{hr}$ and 10 days of age to simultaneously measure GFR by inulin and endogenous creatinine clearances. Inulin and creatinine clearances correlated directly $(r=0.738, P$ $>0.001$ ). The slope of the regression line suggested an overestimation of GFR (inulin clearance) by creatinine clearance at the low GFR range and an underestimation at the high GFR range. The data were divided into two groups by the median inulin clearance $\left(12.5 \mathrm{ml} / \mathrm{min} / 1.73 \mathrm{~m}^{2}\right)$. The ratio of creatinine to inulin clearance was significantly higher in the low GFR group (1.28 \pm 0.16 vs. $0.89 \pm 0.04 \mathrm{SEM}, n=19, P<0.05)$. There was no difference between the two groups in plasma creatinine, birthweight, gestational age, incidence of respiratory distress, or oxygen requirements at the time of the studies. Endogenous creatinine clearance represents a good estimation of GFR (inulin clearance) in low birthweight infants. However, at the low GFR range, it represents an overestimation and at the high GFR range, an underestimation.

\section{Speculation}

In low birthweight infants, tubular secretion of creatinine and plasma chromogens interfere with the accuracy of endogenous creatinine clearance. Tubular secretion of creatinine is probably of relatively greater importance at lower GFR's accounting for an overestimation of GFR by creatinine clearance. At higher GFR's, plasma chromogens are probably of more importance and account, in part, for the underestimation of GFR by creatinine clearance.

The validity of endogenous creatinine clearance as a measure of GFR in adults, children, and infants has long been the subject of discussions and investigations $(1-3,7,8,16)$. Despite methodologic and technical problems (11), it remains the most commonly used laboratory aid for the assessment of glomerular functions in clinical practice. In neonates, the problem is compounded by the presence of noncreatinine interfering substances such as chromogens, including bilirubin, which may raise the plasma creatinine levels, thus, giving falsely low endogenous creatinine clearances. The Jaffé reaction (6), a commonly used method for the determination of creatinine in biologic fluids, does not exclude these interfering substances $(1,2,6,11)$. Although falsely high plasma and urinary creatinine levels may counterbalance each other in the calculation of creatinine clearance, the correlation with true GFR has not been established in low birthweight infants. The purpose of this study was to establish the correlation between endogenous creatinine and inulin clearance as a measure of GFR in low birthweight infants.

\section{MATERIALS AND METHODS}

Thirty-three low birthweight infants (17 males and 16 females, 27 appropriate and 6 small for gestational age) were the subjects of this study. The mean gestational age was 33 wk (range 30-36 wk) and the mean birthweight was $1600 \mathrm{~g}$ (range $1040-2275 \mathrm{~g}$ ). Gestational age was assessed in all infants by the Dubowitz scoring system (4). Thirty-eight studies were performed between $10 \mathrm{hr}$ and 10 days of age. The mean study weight was $1530 \mathrm{~g}$ (range $840-$ $2250 \mathrm{~g}$ ). The study was approved by the institutional human use committee and parental consent was obtained in each case.

Inulin and creatinine clearances simultaneously were performed as follows: uncatheterized timed urine samples were collected on a specially designed neonatal urine collection bed; at the end of each collection, the bladder was creded to assure as complete emptying of the bladder as possible. After a timed discard urine specimen, an initial prime dose of inulin $(50 \mathrm{mg} / \mathrm{kg})$ was administered iv via a peripheral vein followed by a continuous infusion of inulin at a dose of $0.1 \mathrm{mg} / \mathrm{kg} / \mathrm{min}$ using a calibrated infusion pump. Urine collection was continued until 2-6 accurately timed urine collections were obtained. The urine specimens were then pooled and creatinine and inulin concentrations were measured. Three-quarters of $\mathrm{ml}$ of whole blood was obtained by heel puncture, $45 \mathrm{~min}$ after the onset of the inulin infusion for plasma inulin (13) and creatinine. To minimize the quantity of the total whole blood drawn from these infants, one sample was taken for inulin; it has been previously shown that low birthweight infants reach a serum steady-state for inulin $45 \mathrm{~min}$ after the onset of the infusion (13). Serum bilirubin was measured in 26 studies (14). Plasma and urine creatinine and inulin were measured on plasma (19) and urine by a micromethod modified from Folin and $\mathrm{Wu}(6)$ and from Roe et al. (18), respectively. Bilirubin was measured by the Martinek method (14). Inulin and creatinine clearances were calculated by the conventional formulas. All clearances were expressed per $1.73 \mathrm{~m}^{2}$ of body surface area as calculated from a standard nomogram using body length and weight (17).

During the study period, fluid and electrolyte therapy proceeded as determined by the primary physicians caring for the infants. At the time of study, all infants were receiving iv fluids and 26 infants were also receiving oral feedings. The mean fluid intake was 125 $\mathrm{ml} / \mathrm{kg} / 24 \mathrm{hr}$ (range $59-210 \mathrm{ml} / \mathrm{kg} / 24 \mathrm{hr}$ ).

For statistical analysis, the unpaired Student $t$ test was used and the slope of the regression line was compared to an ideal slope of 1 , by the formula $t=1-b / S E b, b=$ slope, $S E b=S E$ of the slope, respectively.

\section{RESULTS}

As shown in Figure 1, inulin and creatinine clearances correlated directly $(r=0.738, P<0.001)$ with the regression equation: $y=3.78+0.66 x$. However, the slope was significantly less than the ideal slope of $1(\mathrm{t}=3.88, P<0.001)$. In fact, the slope of the regression line suggested a trend of overestimation of GFR (inulin clearance) by creatinine clearance at the low GFR range and underestimation of the GFR at the high GFR range. To statisti- 
cally validate this impression, we have arbitrarily divided the data into two groups: those with high or low inulin clearances, i.e., greater or less than $12.5 \mathrm{ml} / \mathrm{min} / 1.73 \mathrm{~m}^{2}$, (the demarcating value of $12.5 \mathrm{ml} / \mathrm{min} / 1.73 \mathrm{~m}^{2}$ is the median of all results).

As seen in Table 1, the ratio of creatinine to inulin clearance was significantly greater in the low GFR group (1.28 $\pm 0.16 \mathrm{vs}$. $0.89 \pm 0.04 \mathrm{M} \pm \mathrm{SEM}, n=19, P<0.05$ ), and there was no significant difference between the two groups in plasma creatinine, birthweight, gestational age, incidence of respiratory distress, and oxygen requirement at the time the studies were performed. Linear regression analysis showed no correlation between birthweight and gestational age with the ratio $\mathrm{Ccr} / \mathrm{Cin}$, respectively. Likewise, there was no correlation between total plasma creatinine and the $\mathrm{Ccr} / \mathrm{Cin}$ ratio or inulin clearance, respectively.

The mean serum bilirubin concentration was $7.6 \pm 0.4 \mathrm{mg} / \mathrm{dl}$ (M $\pm \mathrm{SEM}, n=26$ ) and did not correlate with either plasma creatinine or creatinine clearance.

\section{DISCUSSION}

Several reports have demonstrated a close approximation of creatinine clearance to GFR as measured by inulin at normal levels of glomerular filtration. However, at reduced GFR levels, creatinine clearance overestimates GFR $(1,2,8,16)$, presumably due to the tubular secretion of creatinine in these subjects in whom the reduced glomerular functions were secondary to renal

CREATININE CLEARANCE $\left(\mathrm{mI} / \mathrm{min} / 1.73 \mathrm{M}^{2}\right)$

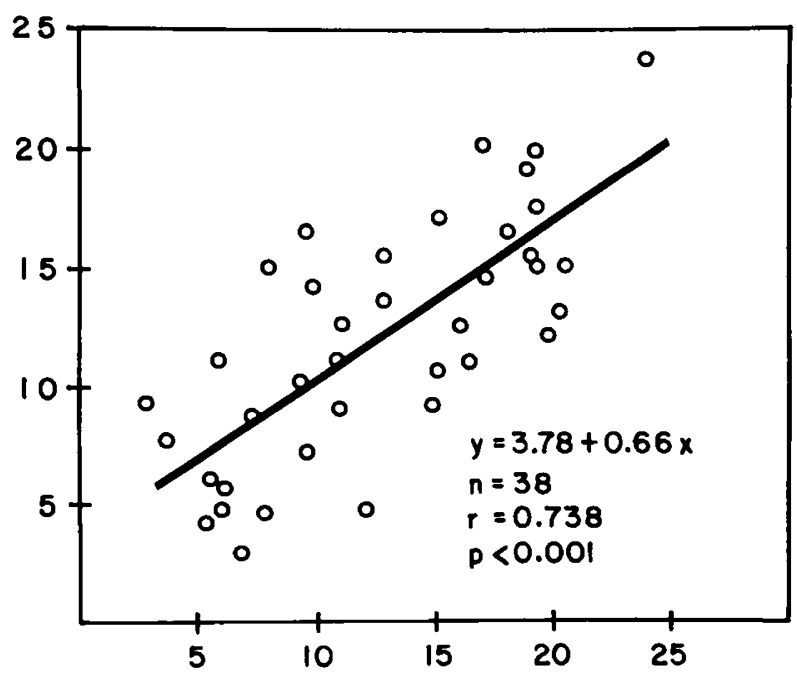

INULIN CLEARANCE $\left(\mathrm{ml} / \mathrm{min} / 1.73 \mathrm{M}^{2}\right)$

Fig. 1. Relationship between inulin and creatinine clearance in low birthweight infants.

Table 1. Relationship of high and low GFR's $\left(C_{i n}\right)$ to validity of creatinine clearance

\begin{tabular}{|c|c|c|}
\hline \multirow[b]{2}{*}{ Parameters } & \multicolumn{2}{|c|}{$\begin{array}{l}\text { Inulin clearance } \\
\left(\mathrm{ml} / \mathrm{min} / 1.73 \mathrm{~m}^{2}\right)\end{array}$} \\
\hline & $\leq 12.5(19)$ & $\geq 12.6$ (19) \\
\hline$\frac{\text { Creatinine clearance }}{\text { Inulin clearance }}$ & $1.28 \pm 0.16$ & $0.89 \pm 0.04^{\prime}$ \\
\hline Plasma creatinine $(\mathrm{mg} / \mathrm{dl})$ & $1.20 \pm 0.063$ & $1.10 \pm 0.052$ \\
\hline Birthweight (kg) & $1.509 \pm 0.070$ & $1.691 \pm 0.078$ \\
\hline Gestation (wk) & $32.0 \pm 0.36$ & $33.0 \pm 0.43$ \\
\hline $\begin{array}{l}\text { RDS } \\
\text { Yes } \\
\text { No }\end{array}$ & $\begin{array}{r}6 \\
12\end{array}$ & $\begin{array}{l}7 \\
8\end{array}$ \\
\hline $\mathrm{O}_{2}$ required during study & $0.23 \pm 0.01$ & $0.23 \pm 0.01$ \\
\hline
\end{tabular}

pathology. In our study, the correlation between inulin and creatinine clearances in low birthweight infants was significant: however, the regression line suggested a trend of overestimation of GFR by creatinine clearance at low GFR's when compared with those at higher values of GFR. The slope of this regression line was significantly different from 1 . This difference was emphasized when the creatinine inulin clearance ratio $\left(\mathrm{C}_{\mathrm{rr}} / \mathrm{C}_{\mathrm{in}}\right)$ of those with lower GFR's was compared with those with higher GFR's. $C_{c \cdot r} /$ $C_{\text {in }}$ ratio should be unity (1.0) if the estimation by creatinine clearance is equal to inulin clearance (GFR); a greater ratio would indicate overestimation and a smaller ratio would indicate an underestimation of GFR by $\mathrm{C}_{\mathrm{t}} \mathrm{r}$. The accuracy of endogenous creatinine clearance as an estimate of GFR is altered by the presence of noncreatinine chromogens (11) and by tubular secretion of creatinine in infants with both ranges of GFR's.

In infants with lower GFR's, $C_{c r}$ overestimated GFR. The reason for this overestimation is very likely due to secretion of creatinine via the tubules. The $\mathrm{C}_{\mathrm{c} r} / \mathrm{C}_{\mathrm{in}}$ ratio was 1.28 , which is considerably higher than the ratio reported for children with GFR's less than $20 \mathrm{ml} / \mathrm{min} / 1.73 \mathrm{~m}^{2}$ (1). This ratio is particularly high, as it is a minimum estimate of tubular creatinine secretion. because these infants also have noncreatinine plasma chromogens (11). Low birthweight infants have an increased extracellular fluid volume (ECF) (5). An increased extracellular fluid space alters many tubular functions $(9,10,15)$. It is possible that an increased ECF may likewise effect tubular creatinine secretion. Because ECF was not determined, this possibility remains speculative. Whether this markedly increased tubular secretion of creatinine is on the basis of developmental immaturity or renal pathologic lesions is not known.

Although GFR's in the infants with relatively higher clearances are significantly lower than those seen in older children, creatinine clearance underestimated GFR $\left(\mathrm{C}_{\mathrm{cr}} / \mathrm{C}_{1}<1.00\right.$ or 0.89 in our series). This ratio is below that reported for older children (1). Although both tubular creatinine secretion and plasma chromogens $(11,19)$ are probably present in this group, tubular secretion of creatinine must be significantly lower permitting plasma chromogens to be of relatively more importance and consequently causing the underestimation of GFR by $C_{\mathrm{c}}$.

There is a variability in the GFR's reported here. The infants studied were between $10 \mathrm{hr}$ and 10 days of life. In low birthweight infants, a low GFR has been reported in the first $24 \mathrm{hr}$ with a significant increase during the first 3 days of life (12).

In our series, no correlation was found between serum bilirubin, plasma creatinine, and creatinine clearance. True creatinine and bilirubin are independent variables, although both may contribute to the total chromogen concentration. The level of bilirubin seen here and the sample size were not of sufficient magnitude to significantly alter the total creatinine concentration.

\section{CONCLUSION}

GFR's were measured simultaneously by inulin and endogenous creatinine clearance in 33 low birthweight infants. Endogenous creatinine clearance represents a good estimation of GFR (inulin clearance) in these infants. Tubular secretion of creatinine and the presence of noncreatinine chromogens in the plasma are probably the two factors that interfere with the accuracy of this measurement in infants.

\section{REFERENCES AND NOTES}

1. Arant, B. S., Edelman. C. M., Spitzer. A.: The congruence of creatinine and inulin clearances in children: use of the Technicon Autoanalyzer. J. Pediatr. 81: 559 (1972).

2. Brouchard, B. H., Travis, L. B.. Cunningham, R. J.. Berger, M., Carvajal, H. F. Simultaneous iothalamate, creatinine, and urea clearances in children with renal disease. Pediatrics, 59: 219 (1977)

3. Dodge, W. F., Travis, L. B., and Daeschner, W. C.: Comparison of endogenous creatinine clearance with inulin clearance. Am. J. Dis. Child. 113:683 (1967).

4. Dubowitz. L. M.. Dubowitz. V.. and Goldberg. (.: Clinical assessment of gestational age in newborn infants. J. Pediatr., 77: I (1970).

5. Friis-Hansen, B.: Body composition during growth. Pediatrics. (Suppl.) 47: 264 (1971).

6. Folin, O., and Wu, H.: A system of blood analysis. J. Biol. Chem., 38: 81 (19/9). 
7. Healy, J. K.: Clinical assessment of glomerular filtration rate by different forms of creatinine clearance and a modified urinary phenolsulphonphthalein excretion test. Am. J. Med.. 44: 348 (1968).

8. Ikkos. D. and Stom. L.: Comparison of endogenous creatinine and inulin clearances in children. Acta Paediatr. Scand.. 44: 426 (1955).

9. Knight. T. F., and Weinman. E. J.: Renal sodium reabsorption following induc tion and recovery from volume expansion. Am. J. Physiol., 233: F416 (1977).

10. Kurtzman. N. A.: Regulation of renal bicarbonate reabsorption by extracellula volume. J. Clin. Invest.. 49: 586 (1970).

II. Lauson. H. D.: Sources of error in plasma creatinine determination. J. Appl Physiol., 4: 227 (1951).

12. Leake. R. D., and Trygstad, C. W.: Glomerular filtration rate during the period of adaptation to extrauterine life. Pediatr. Res., 11: 959 (1977).

13. Leake. R. D.. Trygstad. C. W.. and Oh. W.: Inulin clearance in the newborn infant: relationship to gestational and postnatal age. Pediatr. Res.. 10: 759 (1976).

14. Martinek. R. G.: Improved micromethod for the determination of serum bilirubin. Clin. Chim. Acta. I3: 161 (1966)
15. Massry. S. G., Coburn, J. W.., and Kleeman, C. R.: The influence of extracellular volume expansion on renal phosphate reabsorption in the dog. J. Clin. Invest. 48: 1237 (1969).

16. Mattar, G., Barnett, H. L., McNamara, H., and Lauson, H. D.: Measurement of glomerular filtration rate in children with kidney disease. J. Clin. Invest.. 31: 938 (1952).

17. Nelson. W. E.: Textbook of Pediatrics. 8th Edition, p. 209. (W. B. Saunders Co. Philadelphia, 1964).

18. Roe, J. H. Epstein. J. H. and Goldstein. N. P.: A photometric method for the determination of inulin in plasma and urine. J. Biol. Chem.. 178: 839 (1949).

19. Stonestreet. B. S.. and Oh. W.: Plasma creatinine levels in low birthweight infants during the first 3 months of life. Pediatrics, $61: 788$ (1978).

20. The authors thank William Macomber and Betsy Clement for their technical assistance.

21. Requests for reprints should be addressed to: Dr. William Oh. 50 Maude Street. Providence, RI 02908 USA.

22. Received for publication April 25, 1978.

23. Accepted for publication September 7, 1978. 